\title{
Human immunodeficiency virus infection and autoimmune hepatitis during highly active anti-retroviral treatment: a case report and review of the literature
}

\author{
Hanady Daas ${ }^{1}$, Riad Khatib ${ }^{1 *}$, Haitham Nasser ${ }^{2}$, Farah Kamran ${ }^{3}$, Martha Higgins ${ }^{3}$ and Louis Saravolatz ${ }^{1}$
}

\begin{abstract}
Introduction: The emergence of hepatic injury in patients with human immunodeficiency virus infection during highly active therapy presents a diagnostic dilemma. It may represent treatment side effects or autoimmune disorders, such as autoimmune hepatitis, emerging during immune restoration.

Case presentation: We present the case of a 42-year-old African-American woman with human immunodeficiency virus infection who presented to our emergency department with severe abdominal pain and was found to have autoimmune hepatitis. A review of the literature revealed 12 reported cases of autoimmune hepatitis in adults with human immunodeficiency virus infection, only three of whom were diagnosed after highly active anti-retroviral treatment was initiated. All four cases (including our patient) were women, and one had a history of other autoimmune disorders. In our patient (the one patient case we are reporting), a liver biopsy revealed interface hepatitis, necrosis with lymphocytes and plasma cell infiltrates and variable degrees of fibrosis. All four cases required treatment with corticosteroids and/or other immune modulating agents and responded well.
\end{abstract}

Conclusion: Our review suggests that autoimmune hepatitis is a rare disorder which usually develops in women about six to eight months after commencing highly active anti-retroviral treatment during the recovery of CD4 lymphocytes. It represents either re-emergence of a pre-existing condition that was unrecognized or a de novo manifestation during immune reconstitution.

\section{Introduction}

Impaired immunity in individuals with human immunodeficiency virus (HIV) infection affects the defense mechanisms against pathogens and alters the regulation of autoimmunity [1]. This may lead to the emergence of autoimmune disorders or modification of pre-existing conditions. Several conditions may remit, such as systemic lupus erythematosus (SLE), while others, such as psoriasis, intensify. The development of liver disease during highly active anti-retroviral treatment (HAART) in patients with HIV infection without evidence of coinfection with hepatitis viruses poses a diagnostic

\footnotetext{
* Correspondence: Riad.Khatib@stjohn.org

'Department of Internal Medicine, Division of Infectious Diseases, St John Hospital \& Medical Center, 19251 Mack Avenue, Suite 340, Grosse Pointe Woods, Ml 48236, USA

Full list of author information is available at the end of the article
}

dilemma. This may be due to treatment side effects or to the emergence of autoimmune disorders during immune restoration.

Autoimmune hepatitis (AIH) is rare in patients with HIV infection. Additionally, hepatic involvement is unusual in other common autoimmune disorders. We present the case of a patient with AIH and SLE emerging de novo during HAART and review all previously reported cases of AIH in patients with HIV infection who are undergoing HAART.

\section{Case presentation}

A 42-year-old African-American woman who had been diagnosed with HIV infection in 1989 acquired by heterosexual contact had a fluctuating CD4 count and a viral load secondary to non-adherence. In March 2009, she was extensively counseled on adherence to treatment 
and was started on a new regimen that included emtricitabine/tenofovir and etravirine. She became more compliant with treatment, and her clinical parameters improved. Before March 2009, her CD4 had been 157 cells $/ \mathrm{mm}^{3}$ and her viral load had been 120,000 copies/ $\mathrm{mL}$. One month after treatment adjustment, her CD4 went up to 232 cells $/ \mathrm{mm}^{3}$ and her viral load was undetectable. There was no personal or family history of autoimmune disease.

Six months after treatment adjustment she started to experience gradual right upper quadrant pain associated with intermittent night sweats. Her pain increased in intensity and became intractable. A computed tomographic scan of her abdomen was unremarkable. She was seen in the office with fever and tachycardia and was hospitalized because of possible sepsis and acute abdomen.

Her physical examination revealed that she was febrile (body temperature $\left.102.1^{\circ} \mathrm{F}\right)$, tachycardic (130 beats $/ \mathrm{min}$ ) and hypoxic $\left(\mathrm{O}^{2}\right.$ saturation $84 \%$ on room air). Her chest examination revealed fine bibasilar crackles. Her abdominal examination demonstrated diffuse abdominal tenderness with rebound that was most prominent in the right upper quadrant.

A hepatobiliary iminodiacetic acid scan showed patent biliary ducts with a normal gallbladder ejection fraction. Computed tomography of the chest showed pericardial effusion that was confirmed by a transthoracic echocardiogram.

On day 3 of her hospitalization, she underwent a pericardial window, a pericardial biopsy and a laparoscopy with liver biopsy. The laparoscopy revealed a grossly abnormal liver (Figure 1). The liver biopsy demonstrated a dense portal lymphoplasmacytic infiltrate with multifocal zones of hepatocellular centrilobular necrosis

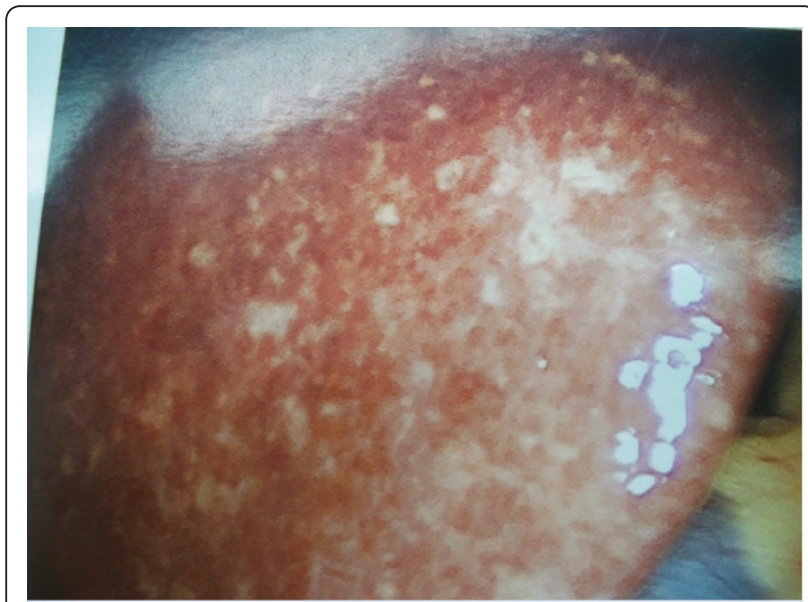

Figure 1 Laparoscopic image of the liver showing diffuse whitish-gray plaque without nodularity or cirrhosis. consistent with AIH (Figure 2). Histological staining for fungi and mycobacterium were negative.

Pertinent laboratory findings in this patient included alanine aminotransferase $1526 \mathrm{U} / \mathrm{L}$, aspartate aminotransferase $777 \mathrm{U} / \mathrm{L}$, international normalized ratio, 1.53; albumin level, $2.7 \mathrm{~g} / \mathrm{dL}$; anti-nuclear antibody (ANA) titer, 1:1280; negative anti-smooth muscle antibody; negative anti-cardiolipin and anti-ribosomal antibodies; anti-double-stranded DNA (anti-dsDNA) titer, 1:160; and immunoglobulin G level, $4600 \mathrm{mg} / \mathrm{dL}$. Her antibodies to hepatitis viruses A, B and C and hepatitis B surface antigen were negative.

Given her clinical picture, her positive laboratory test for ANA and anti-dsDNA and the histopathology of her liver biopsy, a diagnosis of SLE with AIH was made. Her calculated AIH score was 19 (> 15 is considered a definite diagnosis according to the International Autoimmune Hepatitis Group criteria).

The patient was initiated on high-dose steroid therapy (40 mg every 12 hours). By the next day, her abdominal pain had improved, and she was discharged from the hospital on a tapering dose of steroids.

One year after her hospitalization the patient remained in remission, with normal liver function and suppressed HIV viral load. Her steroid therapy was tapered off and stopped completely two months after being discharged from the hospital.

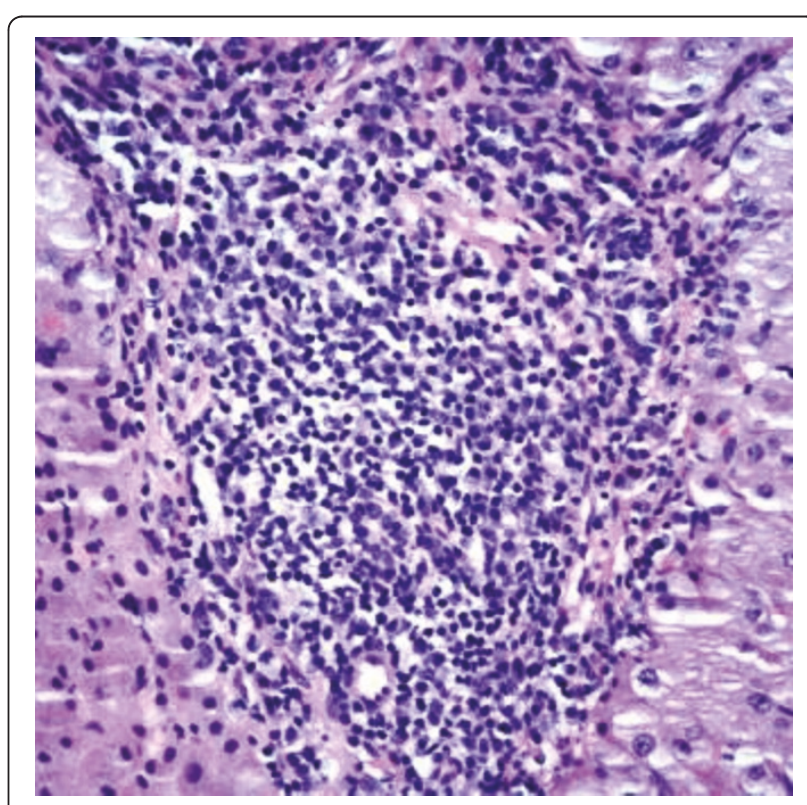

Figure 2 Liver biopsy (hematoxylin and eosin stain) showing dense portal lymphoplasmacytic infiltrate and centrilobular hepatocellular necrosis caused by an acute chronic inflammatory infiltrate suggestive of autoimmune hepatitis. 


\section{Discussion}

Our review of the literature revealed 12 cases of autoimmune hepatitis in patients with HIV infection [2-8]. Three had co-infections with hepatitis $C$ virus and were receiving interferon therapy [6-8] and six more had $\mathrm{AIH}$ before starting HAART and one pediatric patient's data were missing. Only three patients developed AIH after starting HAART, similar to our patient. The clinical characteristics of the reviewed cases and our case are shown in Table 1. All patients who received HAART prior to AIH had a significant rise in CD4 count and undetectable HIV RNA before AIH was diagnosed. Two patients had other concomitant autoimmune diseases, one with Grave's disease and the other with diffuse infiltrative lymphocytic syndrome. This review illustrates that AIH in patients with HIV infection on HAART is rare. It has been encountered in women who had significant elevations in CD4 count, suggesting the emergence of AIH during immune restoration. It presented insidiously with non-specific manifestations. The diagnosis is usually based on AIH score, the absence of other conditions and characteristic histopathological findings.

In patients who develop liver function abnormalities while receiving HAART, it is important to exclude drug-induced liver disease. In our patient, the pathognomonic findings on the liver biopsy and the fact that she had been taking these medications long before she developed symptoms indicate that a drug reaction was not likely.

The prognosis associated with AIH in patients with HIV infection appears to be variable based on a review of 11 out of the 12 reported cases (one reported case's data were missing) of AIH in patients with HIV infection. Two patients died while receiving interferon therapy for hepatitis $\mathrm{C}$ virus that triggered fulminant $\mathrm{AIH}$, and one died as a result of severe Pneumocystis jiroveci pneumonia while receiving high-dose steroids for the treatment of $\mathrm{AIH}$.

Our patient had evidence of SLE in addition to AIH. Whether $\mathrm{AIH}$ is a manifestation of SLE or is unrelated is unclear. Liver involvement associated with $\mathrm{AIH}$ is relatively rare, ranging from $1.2 \%$ to $2 \%$ in patients with SLE who do not have HIV infection [9]. To date, it has not been reported simultaneously with SLE in patients with HIV infection.

The precise mechanism causing the emergence or unmasking of autoimmune conditions in patients who are HIV-positive who commence anti-retroviral therapy is complex and involves multiple cytokines and lymphocyte subsets [10-14]. Th17 cells have recently been implicated in association with chronic autoimmunity phenomena and especially in patients with HIV infection and primates with simian immunodeficiency virus [10]. An additional subset of $\mathrm{CD}^{+}$regulatory $\mathrm{T}$ cells (Treg) has been described. It constitutively expresses CD25 and the transcription factor FoxP3 and has regulatory functions [1]. Although the levels of Treg in patients who are HIV-positive with autoimmune manifestations have not been reported, it seems plausible to propose that preferential depletion of Treg in some individuals could account for the increased autoimmune phenomena in some patients with acquired immunodeficiency syndrome [15-18].

\section{Conclusion}

The present case report and review of the literature describes a rare complication of immune restoration in patients with HIV infection in the era of HAART. Recognizing $\mathrm{AIH}$ in the context of immune reconstitution and initiating appropriate therapy can be lifesaving. Treatment of these patients appears to be similar to that of patients without HIV infection.

Table 1 Characteristics of 11 reported patients with concomitant HIV and AlH $^{\mathrm{a}}$

\begin{tabular}{|c|c|c|c|c|c|c|c|c|}
\hline Case reports & Patient age (years)/gender & Onset & $\mathrm{CD} 4^{\mathrm{b}} / \mathrm{CD}^{\mathrm{c}}$ & $\mathrm{VL}^{\mathrm{b}} / \mathrm{VL}^{\mathrm{c}}$ & AlH score & Outcome & Other Al diseases & ART \\
\hline German et al. [2] & $38^{d} / \operatorname{man}$ & Chronic & $216 / 384$ & $81,000 /<50$ & Probable & Excellent & Vetilligo & Yes \\
\hline Coriat and Podevin [7] & 48/woman & Acute & 250 & Undetectable & Probable & Died & None & Yes \\
\hline \multirow[t]{3}{*}{ Puius et al. [3] } & 29/man & Chronic & $259 / 174$ & $7122 / 27,732$ & Probable & Excellent & None & Yes \\
\hline & $45^{\mathrm{d}} /$ woman & Chronic & $253 / 297$ & $8687 /<50$ & Probable & Excellent & DILS & Yes \\
\hline & 65/woman & Acute & $200 / 922$ & Undetectable/< 75 & Definite & Excellent & None & Yes \\
\hline O'Leary et al. [4] & $44^{d} /$ woman & Chronic & $269 / 526$ & $4927 /<50$ & Definite & Excellent & Grave's disease & Yes \\
\hline \multirow[t]{4}{*}{ Wan et al. [5] } & 56/man & Chronic & 331/NA & $232,734 / \mathrm{NA}$ & Probable & Died & None & \\
\hline & 54/man & Chronic & $357 / 213$ & 5104/NA & Probable & Probable & Cirrhosis & Yes \\
\hline & 55/woman & Chronic & 174/NA & $<50 / \mathrm{NA}$ & Probable & Probable & Poor & Yes \\
\hline & 49/woman & Acute & 286/NA & $69,318 / \mathrm{NA}$ & Definite & Definite & Died & Yes \\
\hline Our patient & $42^{d} /$ woman & Acute & $157 / 232$ & $120,000 /<50$ & Definite & Excellent & SLE & Yes \\
\hline
\end{tabular}

${ }^{\mathrm{a}}$ Two patients are not included because of lack of complete clinical data. HIV = human immunodeficiency virus; $\mathrm{AlH}=$ autoimmune hepatitis; $\mathrm{Al}$, autoimmune; ART = antiretroviral treatment; VL = viral load; DILS = diffuse infiltrative lymphocytic syndrome; SLE = systemic lupus erythematosus; ${ }^{b}$ prior to initiating highly active antiretroviral treatment (HAART); ${ }^{c}$ after initiating HAART; ${ }^{d}$ patients with significant viral suppression on HAART who developed AlH. 


\section{Consent}

Written informed consent was obtained from the patient for publication of this case report and any accompanying images. A copy of the written consent is available for review by the Editor-in-Chief of this journal.

\section{Abbreviations}

AlH: autoimmune hepatitis; HAART: highly active anti-retroviral therapy; HIV: human immunodeficiency virus; $\mathrm{VL}$ : viral load.

\section{Author details}

'Department of Internal Medicine, Division of Infectious Diseases, St John Hospital \& Medical Center, 19251 Mack Avenue, Suite 340, Grosse Pointe Woods, Ml 48236, USA. ${ }^{2}$ Department of Pathology, St John Hospital \& Medical Center, 22101 Moross Road, Detroit, MI 48236, USA. ${ }^{3}$ Department of Internal Medicine, St John Hospital \& Medical Center, 22101 Moross Road, Detroit, Ml 48236, USA.

\section{Authors' contributions}

HD wrote the manuscript, collected the images and obtained consent from the patient to publish this case report. RK reviewed the literature and edited the manuscript. FK coordinated care while this patient was hospitalized. LS provided inpatient care for the patient and edited the manuscript. HN reviewed and provided legends for the pathological images. $\mathrm{MH}$ reviewed the pathological specimens and made the initial diagnosis. All authors read and approved the final manuscript.

\section{Competing interests}

The authors declare that they have no competing interests.

Received: 29 September 2010 Accepted: 25 June 2011

Published: 25 June 2011

\section{References}

1. Elhed A, Unutmaz D: Th17 cells and HIV infection. Curr Opin HIV AIDS 2010, 5:146-150.

2. German V, Vassiloyanakopoulos A, Sampaziotis D, Giannakos G: Autoimmune hepatitis in an HIV infected patient that responded to antiretroviral therapy. Scand J Infect Dis 2005, 37:148-151.

3. Puius YA, Dove LM, Brust DG, Shah DP, Lefkowitch JH: Three cases of autoimmune hepatitis in HIV-infected patients. J Clin Gastroenterol 2008, 42:425-429.

4. O'Leary JG, Zachary K, Misdraji J, Chung RT: De novo autoimmune hepatitis during immune reconstitution in an HIV-infected patient receiving highly active antiretroviral therapy. Clin Infect Dis 2008, 46 e12-e14.

5. Wan DW, Marks K, Yantiss RK, Talal AH: Autoimmune hepatitis in the HIVinfected patient: a therapeutic dilemma. AIDS Patient Care STDS 2009, 23:407-413.

6. Vispo E, Maida I, Moreno A, Barreiro P, Soriano V: Autoimmune hepatitis induced by pegylated interferon in an HIV-infected patient with chronic hepatitis C. J Antimicrob Chemother 2008, 62:1470-1472.

7. Coriat $R$, Podevin P: Fulminant autoimmune hepatitis after successful interferon treatment in an HIV-HCV co-infected patient. Int J STD AIDS 2008, 19:208-210.

8. Cazanave C, Rakotondravelo S, Morlat P, Blanco P, Bonnet F, Beylot J: Autoimmune hepatitis in a HIV-HCV co-infected patient: diagnostic and therapeutic difficulties in French. Rev Med Interne 2006, 27:414-419.

9. Youssef WI, Tavill AS: Connective tissue diseases and the liver. J Clin Gastroenterol 2002, 4:345-349.

10. Yao Q, Frank M, Glynn M, Altman RD: Rheumatic manifestations in HIV-1 infected in-patients and literature review. Clin Exp Rheumatol 2008, 26:799-806.

11. Wanchu A, Sud A, Singh S, Bambery P: Human immunodeficiency virus infection in a patient with systemic lupus erythematosus. J Assoc Physicians India 2003, 51:1102-1104.

12. Calza L, Manfredi R, Colangeli V, D'Antuono A, Passarini B, Chiodo F: Systemic and discoid lupus erythematosus in HIV-infected patients treated with highly active antiretroviral therapy. Int J STD AIDS 2003, 14:356-359.

13. Sommer S, Piyadigamage A, Goodfield MJ: Systemic lupus erythematosus or infection with HIV, or both? Clin Exp Dermatol 2004, 29:393-395.

14. Walker UA, Tyndall A, Daikeler T: Rheumatic conditions in human immunodeficiency virus infection. Rheumatology (Oxford) 2008, 47:952-959.

15. Weiss $L$, Letimier FA, Carriere M, Maiella S, Donkova-Petrini V, Targat B, Benecke A, Rogge L, Levy Y: In vivo expansion of naive and activated $\mathrm{CD}^{+} \mathrm{CD}^{2} 5^{+} \mathrm{FOXP3}^{+}$regulatory $\mathrm{T}$ cell populations in interleukin-2-treated HIV patients. Proc Natl Acad Sci USA 2010, 107:10632-10637.

16. Lim A, French MA, Price $P: C D 4+$ and CD8+ T cells expressing FoxP3 in HIV-infected patients are phenotypically distinct and influenced by disease severity and antiretroviral therapy. J Acquir Immune Defic Syndr 2009, 51:248-257.

17. Ji J, Cloyd MW: HIV-1 binding to $\mathrm{CD} 4$ on $\mathrm{CD} 4{ }^{+} \mathrm{CD} 25^{+}$regulatory T cells enhances their suppressive function and induces them to home to, and accumulate in, peripheral and mucosal lymphoid tissues: an additional mechanism of immunosuppression. Int Immunol 2009, 21:283-294.

18. Jiao Y, Fu J, Xing S, Fu B, Zhang Z, Shi M, Wang X, Zhang J, Jin L, Kang F, Wu H, Wang FS: The decrease of regulatory $T$ cells correlates with excessive activation and apoptosis of $\mathrm{CD}^{+} \mathrm{T}$ cells in HIV-1-infected typical progressors, but not in long-term non-progressors. Immunology 2009, 128(1 Suppl):e366-e375.

\section{doi:10.1186/1752-1947-5-233}

Cite this article as: Daas et al:: Human immunodeficiency virus infection and autoimmune hepatitis during highly active anti-retroviral treatment: a case report and review of the literature. Journal of Medical Case Reports 2011 5:233.

\section{Submit your next manuscript to BioMed Central and take full advantage of:}

- Convenient online submission

- Thorough peer review

- No space constraints or color figure charges

- Immediate publication on acceptance

- Inclusion in PubMed, CAS, Scopus and Google Scholar

- Research which is freely available for redistribution

Submit your manuscript at www.biomedcentral.com/submit
Ciomed Central 